Results Three hundred and four women met criteria: 200 underwent laparotomy and 104 MIS. Women in the MIS group were younger, had lower rate of diabetes and lower CA-125 level. Women who underwent laparotomy had higher grade EC and more advanced stage disease; Odds Ratio (OR) and 95\% Confidence Interval (CI) $0.34(0.21-0.56)$ and 0.56 (0.34-0.92), respectively. Brachytherapy rate was comparable between groups $(p=0.715)$. In a multivariable analysis, including age, comorbidities, disease stage, tumor grade and lymphvascular space invasion, MIS was not associated with an increased risk for recurrence, progression or decreased overall survival. However, patients operated by MIS had higher risk to recur locally (vaginal cuff or pelvic) (26.9\% vs. $16.5 \%$, $\mathrm{p}=0.032$, OR, 1.86, 95\% CI 1.05-3.30). MIS was the only independent factor associated with local recurrence, adjusted OR, 2.09, 95\% CI 1.12-3.90.

Conclusions In women with stage II-IIIc EC, MIS was associated with an increased risk for local recurrence compared to laparotomy.

\section{7/\#202 RECURRENCE AND SURVIVAL AFTER LAPAROSCOPY VERSUS LAPAROTOMY IN EARLY- STAGE ENDOMETRIAL CANCER: LONG-TERM OUTCOMES OF A RANDOMISED TRIAL}

${ }^{1} \mathrm{M}$ Van Suijlichem, ${ }^{1} \mathrm{~B}$ Reeinties ${ }^{*},{ }^{2} \mathrm{~J}$ Woolderink, ${ }^{3} \mathrm{M}$ Bongers, ${ }^{4} \mathrm{~L}$ Paulsen, ${ }^{5} \mathrm{PVD}$ Hurk ${ }^{6} \mathrm{~A}$ Kraayenbrink, ${ }^{7} \mathrm{M}$ Apperloo, ${ }^{8} \mathrm{~B}$ Slangen, ${ }^{9} \mathrm{~T}$ Schukken, ${ }^{10} \mathrm{~F}$ Tummers, ${ }^{11} \mathrm{P}$ Van Kesteren, ${ }^{12} \mathrm{~J}$ Huirne, ${ }^{13} \mathrm{D}$ Boskamp, ${ }^{1} \mathrm{M}$ Mourits, ${ }^{14} \mathrm{G}$ De Bock. ${ }^{1}$ University Medical Center Groningen, Gynaecology and Obstetrics, Groningen, Netherlands; ${ }^{2}$ Martini Hospital Groningen, Gynaecology and Obstetrics, Groningen, Netherlands; ${ }^{3}$ Maxima Medical Center Veldhoven, Gynaecology and Obstetrics, Veldhoven, Netherlands; ${ }^{4}$ Wilhelmina Hospital Assen, Gynaecology and Obstetrics, Assen, Netherlands; ${ }^{5} \mathrm{Nij}$ Smellinghe Hospital Drachten, Gynaecology and Obstetrics, Drachten, Netherlands; ${ }^{6}$ Rijnstate Hospital Arnhem, Gynaecology and Obstetrics, Arnhem, Netherlands; ${ }^{7}$ Medical Center Leeuwarden, Gynaecology and Obstetrics, Leeuwarden, Netherlands; ${ }^{8}$ Maastricht University Medical Center, Gynaecology and Obstetrics, Maastricht, Netherlands; ${ }^{9}$ Antonius Hospital Sneek, Gynaecology and Obstetrics, Sneek, Netherlands; ${ }^{10}$ Leiden University Medical Center, Gynaecology and Obstetrics, Leiden, Nepal; ${ }^{11}$ Onze Lieve Vrouwe Gasthuis Amsterdam, Gynaecology and Obstetrics, Amsterdam, Netherlands; ${ }^{12}$ Amsterdam University Medical Center, Gynaecology and Obstetrics, Amsterdam, Netherlands; ${ }^{13}$ VieCuri Medical Center Venlo, Gynaecology and Obstetrics, Venlo, Netherlands; ${ }^{14}$ University Medical Center Groningen, Epidemiology, Groningen, Netherlands

\subsection{6/ijgc-2021-IGCS.7}

Objectives Laparoscopic hysterectomy is accepted globally as the standard treatment option for early-stage endometrial cancer, but there is limited long-term survival data. We compared the survival outcomes of total laparoscopic hysterectomy (TLH) and total abdominal hysterectomy (TAH) for early-stage endometrial cancer up to 5 years after each procedure.

Methods Follow-up of a multi-centre, randomised controlled trial comparing TLH and TAH, without routine lymphadenectomy, for women with stage I endometrial cancer. Enrolment was between 2007 and 2009 by 2:1 randomisation to TLH or TAH. Assessed at 5 years, the primary outcome was the disease-free survival (DFS) and the secondary outcomes were the overall survival (OS), disease-specific survival (DSS), and primary site of recurrence. Multivariable Cox regression analyses were adjusted for age, stage, and grade, with adjusted hazard ratios (aHR) and 95\% confidence intervals (95\% CI) reported.
Results In total, 279 women underwent procedures and 263 (94\%) of these had follow-up data. For the TLH $(n=185)$ and TAH $(n=94)$ groups, DFS $(90.3 \%$ vs $84.1 \%$; aHR[recurrence], 0.76 ; 95\% CI, $0.35-1.66)$, OS (89.2\% vs $82.8 \%$; aHR [death], 0.64; 95\%CI, 0.33-1.27), and DSS (95.0\% vs $89.8 \%$; aHR[death], 0.74; 95\%CI, 0.28-1.99) were comparable at 5 years. There were no port-site or wound metastases, and local recurrence rates were comparable.

Conclusions No study has reported on survival among women with early-stage endometrial cancer treated by TLH or TAH without routine lymphadenectomy. Survival outcomes (DFS, OS and DSS) were comparable between the treatment options at 5 years, supporting the widespread use of TLH as a primary treatment for early-stage, low-grade endometrial cancer.

\section{Awards Ceremony \& Plenary 4: Seminal Abstract Presentations}

\section{8/\#785 A MULTICENTER, OPEN-LABEL, RANDOMIZED, PHASE 3 STUDY TO COMPARE THE EFFICACY AND SAFETY OF LENVATINIB IN COMBINATION WITH PEMBROLIZUMAB VS TREATMENT OF PHYSICIAN'S CHOICE IN PATIENTS WITH ADVANCED ENDOMETRIAL CANCER: STUDY 309/ KEYNOTE-775}

${ }^{1} \mathrm{~V}$ Makker* ${ }^{2} \mathrm{~N}$ Colombo, ${ }^{3} \mathrm{~A}$ Casado Herráez, ${ }^{4} \mathrm{~A}$ Santin, ${ }^{5} \mathrm{E}$ Colomba, ${ }^{6} \mathrm{D}$ Miller, ${ }^{7} \mathrm{~K}$ Fujijwara, ${ }^{8} \mathrm{~S}$ Pignata, ${ }^{9} \mathrm{~S}$ Baron-Hay, ${ }^{10}$ Ray-Coquard, ${ }^{11} \mathrm{R}$ Shapira, ${ }^{12} \mathrm{~K}$ Ushijima, ${ }^{13} \mathrm{~J}$ Sakata, ${ }^{12} \mathrm{~K}$ Yonemori, ${ }^{14} \mathrm{YM}$ Kim, ${ }^{15} \mathrm{EM}$ Guerra, ${ }^{16} \mathrm{UA}$ Sanli, ${ }^{17} \mathrm{M}$ Mccormack, ${ }^{18} \mathrm{~J}$ Huang, ${ }^{19}$ AD Smith. ${ }^{1}$ Memorial Sloan Kettering Cancer Center, Medicine, New York, USA; ${ }^{2}$ University of Milan-Bicocca and European Institute of Oncology, Milan, Gynecologic Oncology, Milan, Italy; ${ }^{3}$ San Carlos University Teaching Hospital, Department of Medical Oncology, Madrid, Spain; ${ }^{4}$ Yale University School of Medicine, Department of Obstetrics, Gynecology and Reproductive Sciences, New Haven, USA; ${ }^{5}$ Gustave Roussy Cancerology Institute, Department of Cancer Medicine, Villejuif, GINECO group, France; ${ }^{6}$ University of Texas Southwestern Medical Center, Obstetrics and Gynecology, Dallas, USA; ${ }^{7}$ Saitama Medical University International Medical Center, Department of Gynecologic Oncology, Hidaka, Japan; ${ }^{8}$ Instituto Nazionale Tumori IRCCS Fondazione G Pascale, Department of Uro-gynaecological Oncology, Napoli, Italy; ${ }^{9}$ Royal North Shore Hospital, Tba, St. Leonards, Australia; ${ }^{10}$ University Claude Bernard Lyon I, Medical Oncology, Lyon, France; ${ }^{11}$ Sheba Medical Center, Tba, TBA, Israel; ${ }^{12}$ Kurume University School of Medicine, Department of Obstetrics and Gynecology, Kurume, Japan; ${ }^{13}$ Aichi Cancer Center Hospital, TBA, Japan; ${ }^{14}$ Asan Medical Center, University of Ulsan, Department of Obstetrics and Gynecology, Seoul, Korea, Republic of; ${ }^{15}$ Hospital Universitario Ramón y Cajal, TBA, Madrid, Spain;

${ }^{16}$ Ege University, TBA, Izmir, Turkey; ${ }^{17} 18$ University College London Hospitals NHS Foundation Trust, TBA, London, UK; ${ }^{18}$ Eisai Inc, Woodcliff Lake, NJ, USA; ${ }^{19}$ Eisai Ltd., TBA, Hatfield, UK

\subsection{6/ijgc-2021-IGCS.8}

Objectives Results from a phase $1 \mathrm{~b} / 2$ study showed lenvatinib $(\mathrm{LEN})+$ pembrolizumab (pembro) has efficacy in patients (pts) with advanced endometrial carcinoma following prior treatment. Here, we describe the phase 3 study results of LEN + pembro vs treatment of physician's choice (TPC) following platinum-based therapy in pts with advanced endometrial cancer $(\mathrm{aEC})$.

Methods Pts were randomized (1:1) to receive LEN $20 \mathrm{mg}$ orally QD + pembro $200 \mathrm{mg}$ IV Q3W or TPC (doxorubicin at $60 \mathrm{mg} / \mathrm{m} 2 \mathrm{IV}$ Q3W or paclitaxel at $80 \mathrm{mg} / \mathrm{m} 2$ IV QW [3 